\title{
Marginal Fit Comparison of Hot Isostatic Pressed and Non-Hot Isostatic Pressed Zirconia Copings with Three Different Marginal Finish Lines Fabricated with Two Different CAD-CAM Systems
}

\author{
Cumhur Korkmaz ${ }^{1}$, Cumhur Sipahi ${ }^{1}$, Arzu Atay ${ }^{1}$, Aydin Gulses ${ }^{2}$ and Banu Karayazgan Saracoglu ${ }^{3}$ \\ ${ }^{1}$ Department of Prosthodontics, University of Health Sciences, Turkey \\ ${ }^{2}$ Department of Oral and Maxillofacial Surgery, Turkey
}

${ }^{3}$ Department of Prosthodontics, Okan University, Turkey

Submission: September 07, 2017; Published: October 24, 2017

*Corresponding author: Cumhur Korkmaz, Department of Prosthodontics, University of Health Sciences, Faculty of Dentistry, Assistant Professor, Istanbul, Turkey, Tel: +905325496590; Email: cmhkorkmaz@hotmail.com

\begin{abstract}
Purpose: The aim of this study was to compare the marginal fit of hot isostatic pressed (HIP) and non-hot isostatic pressed (NON-HIP) zirconia copings with three different marginal finish lines fabricated with two different CAD-CAM systems.

Methods: 60 pcs. Stainless steel specimens, which are $6 \mathrm{~mm}$ crown length $2 \mathrm{~mm}$ finish lines width and 60 degree axial wall inclination angle were prepared. These specimens were prepared 3 different marginal finish lines as shoulder finish line (SHO), chamfer finish line (CHA), bevel finish line (BEV). 30 NON-HIP zirconia copings with Cerec in Lab System, and 30 HIP zirconia copings with DCS Precedent System were fabricated with shoulder, chamfer and bevel finish lines as 10 each groups. Totally 60 zirconia coping specimens were randomly assigned in 6 experimental groups $(\mathrm{n}=10)$.
\end{abstract}

Results: Marginal gap measurements were performed using a stereomicroscope with $\mathrm{x} 150$ magnification. The average measurement values were obtained as follows, respectively: Group SHO/HIP $(35,8 \pm 13,5 \mu \mathrm{m})<$ Group CHA/HIP $(44,3 \pm 13,3 \mu \mathrm{m})<$ Group BEV/HIP $(55,7 \pm 27,6 \mu \mathrm{m})$ $<$ Group CHA/NHIP $(60,2 \pm 24,4 \mu \mathrm{m})<$ Group SHO/NHIP $(85,6 \pm 25,6 \mu \mathrm{m})<$ Group BEV/NHIP $(86,6 \pm 35,8 \mu \mathrm{m})$. Statistically significant difference was found between HIP and NON-HIP groups $(\mathrm{p}<0.001)$, and between groups with different finish line $(\mathrm{p}<0.001)$.

Conclusion: The marginal gap of zirconium frameworks has been affected by the type of finish line and different CAD-CAM systems.

Keywords: Cad-cam; Marginal adaptation; Zirconium oxide

Abbreviations: CAD: Computer-Aided Design; CAM: Computer Aided Manufacturing; HIP: Hot Isostatic Pressed; NON-HIP: Non-Hot Isostatic Pressed; SHO: Shoulder; CHA: Chamfer; BEV: Bevel

\section{Introduction}

Owing to their superior aesthetic and functional properties fixed ceramic restorations became an integral part of the daily dental practice. However, it is well known that porcelain fused to metal restorations can cause metal-ion discoloration, corrosion, prevention of the light transmission and allergic reactions. [1-7] Therefore, aesthetically superior metal free porcelain systems have been developed and gained their popularity in the last decade with the use of all-ceramic framework materials such as lithium dislocate, aluminum oxide and zirconium oxide [8-10]. Apart from their mechanical strength other important issues related to physical properties of ceramic restorations are their biocompatibility and marginal adaptation. Marginal adaptation in fixed restorations is thought to be one of the most decisive factors in long-term success of the prosthetic rehabilitation [11]. Marginal gaps around fixed restorations might result in plaque accumulation, micro leakage, decrease in gingival curricular fluid, caries formation and bone loss associated with periodontal destruction. [12,13]. A literature survey revealed that, up to $120 \mu \mathrm{m}$ gap around a fixed restoration could be accepted as within clinically acceptable limits [11,14-17]. In the last two decades the use of computer-aided design (CAD) and computer aided manufacturing (CAM) technologies allowed manufacturing of highly resistant ceramic materials which are serving satisfactory results in terms of aesthetics and durability $[18,19]$. There are two different types of CAD/CAM systems. The 
first type is the use of fully sintered (hot isostatically pressed) dense blocks. The future of this system makes direct machining by using grinding machine with high strength. The other type is the use of partially sintered blocks (non-hot isostatically pressed). This system need post-sintering to obtain a final product with sufficient strength. Currently different zirconium oxide ceramic systems such as Cercon (Dentsply), Precident DCS (DCS Dental AG), Lava (3M ESPE), Procera All Zirkon (Nobel Biocare) and Cerec inlab (Cerec inLab® MC XL, Sirona Dental Systems, Bensheim, Germany) were also developed [20-22]. The aim of this in-vitro study was to compare the marginal fit of hot isostatic pressed (HIP) and non-hot isostatic pressed (NON-HIP) zirconia copings with 3 different marginal finish lines fabricated with two different CADCAM systems. It was hypothesized that the frameworks fabricated with shoulder marginal finish line and by DCS Precident ${ }^{\circledR}$ CAD/ CAM system would be associated with less marginal gap.

\section{Materials and Methods}

In order to simulate prepared teeth, 60 stainless steel specimens were fabricated in CNC lathe (Samsung PL 15A/300, Ankara, Turkey). Specimens had a length of $6 \mathrm{~mm}$, marginal width of $1.2 \mathrm{~mm}$ and preparation angle of 6 degrees. Three finish line designs were prepared among 3 experimental groups: shoulder (SHO), chamfer (CHA) and bevel (BEV) $(n=20)$. These 3 experimental groups were divided to two sub-groups as HIP and NON-HIP according to the zirconium core material type and production methods (SHO/HIP, SHO/NHIP, CHA/HIP, CHA/NHIP, $\mathrm{BEV} / \mathrm{HIP}$ and BEV/NHIP). HIP zirconia specimens were produced by DCS Precedent ${ }^{\circledR}$ CAD-CAM system and NON- HIP zirconia specimens were produced by Cerec in lab® CAD-CAM system (Figure 1).

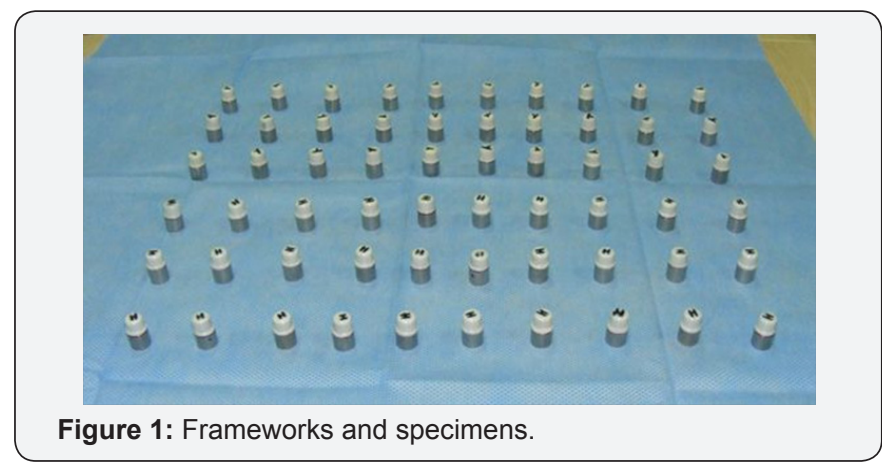

\section{Preparation of frameworks with Cerec in Lab® system}

For the preparation of NON-HIP zirconium frameworks with Cerec in Lab® system, (Cerec in Lab® MC XL, Serena Dental Systems, Blenheim, Germany) surfaces of stainless steel specimens were coated with the titanium oxide powder (Powder Cerec, Vita, Germany). Images of specimens coated titanium oxide were transferred and designed via digital image device of Cerec in Lab ${ }^{\circledR}$ system. Marginal limits of restorations on digital impressions were determined and restorations within the marginal limits were composed in digital platform. Thicknesses of frameworks were adjusted as $0.5 \mathrm{~mm}$ on Cerec in Labß software program. Ceramic blocks (Vita In-Ceram YZ Zirconia, VITA Zahnfabrik) were placed to the milling section of the device. After dimensional values of specimens were transferred to milling section of the device milling process by calibrating has started. After milling, the frameworks have sintered to achieve the final density and maximum strength of the material.

\section{Preparation of frameworks with DCS precedent system}

HIP zirconia frameworks were fabricated from fully-sintered DC-zirconia blocks by using DCS Precedent ${ }^{\circledR}$ CAD-CAM systems (DCS-Precedent ${ }^{\circledR}$, DCS Dental AG and CH-Allschwill, Germany). Surfaces of specimens were scanned with laser scanner and configuration of the frameworks was created digitally. The milling process was completed in approximately 3 hours.

\section{Marginal Gap Measurements}

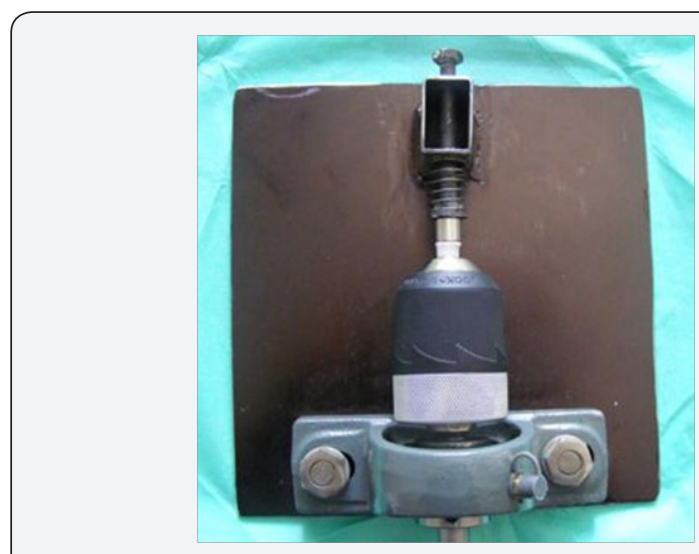

Figure 2: The device designed for measurements.

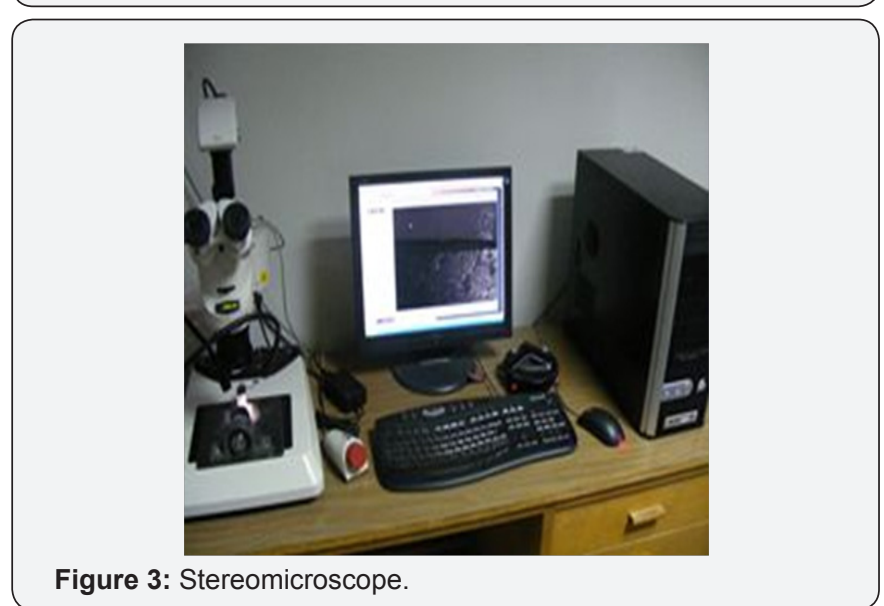

These measurements were performed at 32 different points across the entire circumference of each framework. A special device was designed to keep constant forces and standard positioning of the specimens under the microscope (Figure 2). Measurements were conducted by a stereomicroscope (Leica MZ 16 FA, Wetzlar, Germany) via a special software (Leica Image Manager IM 1000V 4.0 R117, Wetzlar, Germany) with a x250 magnification integrated with a digital camera (Leica DFC 420, Wetzlar, Germany) at General Directorate of Mineral Research and Exploration Department of Mineralogy and Petrography Laboratory (Figure 3). Examination of marginal fit of frameworks was performed under a stereomicroscope 
with x150 magnification. The images of all frameworks were taken with the same magnification and standard position under stereomicroscope. Prior to measurements of the marginal gaps in order to easily view the marginal zone, the marginal edges of specimens were painted by a red marking pencil with an angle of 45 odegree (Figure 4). The photographs were taken at 8 points. 32 measurement values were taken from each specimen with 4 measurement values on each selected point (Figure 5). 960 measurement values for the each group were obtained. In case the guide point resembled a non-uniform marginal discrepancy or cracked area was observed during the analysis of the photos for measurement a different point was chosen at the same photo for the measurement in order to eliminate measurements without representative marginal discrepancies.

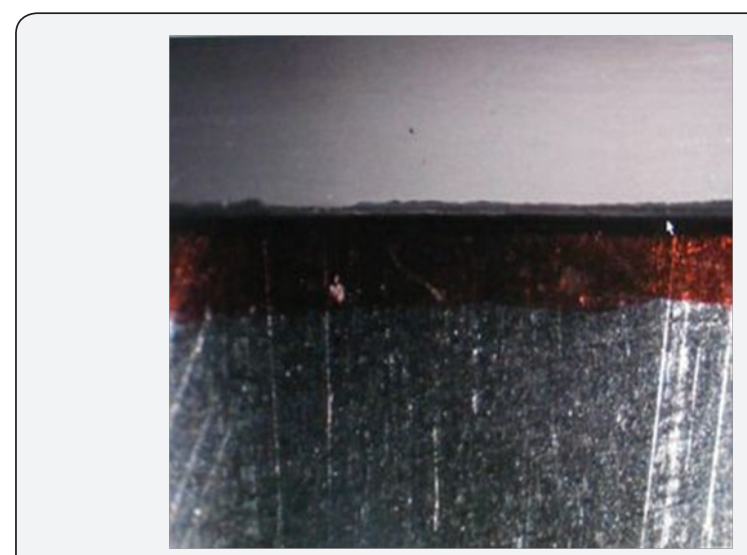

Figure 4: The painted marginal edge and the captured image of marginal gap.

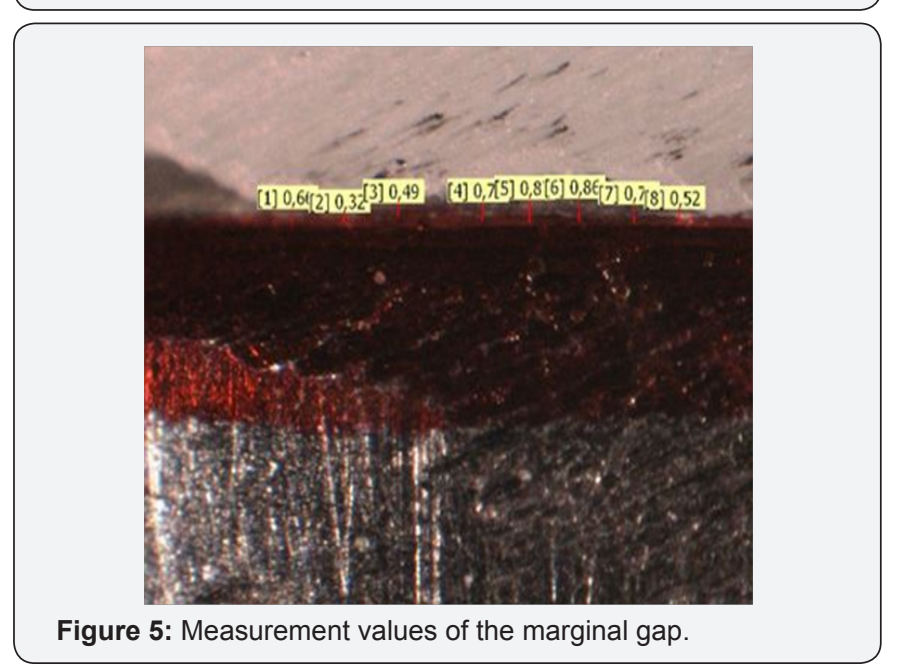

\section{Statistical analysis}

SPSS 15.0 (SPSS Inc. USA) software was used for the statistical analysis. For the identification of data, mean, median, minimummaximum and standard deviation values were calculated. Compliance of continuous variables with normal distribution was analyzed by using the Kolmogorov-Smirnov test. Kruskal-Wallis test was used in comparison of multiple groups. Comparison of main groups was made by Mann-Whitney U test with Bonferroni correction. Statistically $\mathrm{p}<0.05$ was considered as significant.

\section{Results}

Measurements, means, standard deviation, median, minimum- maximum values among NON-HIP groups (SHO/NHIP, CHA/NHIP, BEV/NHIP) and HIP (SHO/HIP, CHA/HIP, BEV/HIP) groups were shown in micrometer $(\mu \mathrm{m})$ in Table 1-2. Marginal gap values of different finish lines were shown in Table 3. The comparison of (SHO/NHIP) \& (SHO/HIP), (CHA/NHIP) \& (CHA/ HIP), (BEV/NHIP) \& (BEV/HIP) groups are shown in Figure 6-8. Marginal gap values of six experimental groups were listed from smaller to larger as follows: SHO/HIP $35,8 \pm 13,5 \mu \mathrm{m}<\mathrm{CHA} /$ HIP 44,3 $\pm 13,3 \mu \mathrm{m}<\mathrm{BEV} / \mathrm{HIP} 55,7 \pm 27,6 \mu \mathrm{m}<\mathrm{CHA} /$ NHIP 60,2 $\pm 24,4 \mu \mathrm{m}<$ SHO/NHIP $85,6 \pm 25,6 \mu \mathrm{m}<$ BEV/NHIP $86,6 \pm 35,8 \mu \mathrm{m}$. The comparison between the same kinds of finish lines prepared with different systems revealed statistically significant differences $(\mathrm{p}<0,001)$ (Table 4).

Table 1: Marginal gap values obtained in NON-HIP groups $(\mu \mathrm{m})$.

\begin{tabular}{|c|c|c|c|c|c|c|}
\hline $\begin{array}{c}\text { Sub } \\
\text { Groups }\end{array}$ & Specimens & Mean & $\begin{array}{l}\text { Standard } \\
\text { Deviation }\end{array}$ & Median & Min. & Max. \\
\hline \multirow{10}{*}{$\begin{array}{l}\text { SHO/ } \\
\text { NHIP }\end{array}$} & 1 & 72,08 & 29,00 & 69,00 & 25,5 & 125,5 \\
\hline & 2 & 63,66 & 21,93 & 56,25 & 31,5 & 121,5 \\
\hline & 3 & 87,75 & 16,74 & 89,25 & 46,5 & 117,5 \\
\hline & 4 & 69,50 & 16,20 & 73,50 & 36 & 96 \\
\hline & 5 & 95,83 & 15,72 & 99,75 & 66 & 118 \\
\hline & 6 & 90,91 & 23,17 & 90,25 & 57,5 & 165 \\
\hline & 7 & 78,60 & 27,96 & 73,50 & 36 & 132,5 \\
\hline & 8 & 111,13 & 13,97 & 114 & 78 & 132 \\
\hline & 9 & 83,88 & 22,27 & 78,75 & 43,5 & 129 \\
\hline & 10 & 102,75 & 22,93 & 114,75 & 57 & 136,5 \\
\hline \multirow{10}{*}{$\begin{array}{l}\text { CHA/ } \\
\text { NHIP }\end{array}$} & 1 & 77,20 & 24,44 & 73,50 & 45,5 & 130,5 \\
\hline & 2 & 58,86 & 17,62 & 57,75 & 28,5 & 100,5 \\
\hline & 3 & 39,91 & 7,81 & 39 & 27 & 55,5 \\
\hline & 4 & 66,43 & 28,41 & 57,75 & 25,5 & 121,5 \\
\hline & 5 & 61,21 & 25,13 & 57 & 25,5 & 120,5 \\
\hline & 6 & 67,01 & 28,13 & 68,50 & 25,5 & 121,5 \\
\hline & 7 & 49,23 & 16,31 & 48 & 25,5 & 88,5 \\
\hline & 8 & 53,98 & 18,41 & 57 & 16,5 & 88,5 \\
\hline & 9 & 57,03 & 24,91 & 57 & 25,5 & 108 \\
\hline & 10 & 71,21 & 24,80 & 68 & 33 & 117 \\
\hline \multirow{10}{*}{$\begin{array}{l}\text { BEV/ } \\
\text { NHIP }\end{array}$} & 1 & 97,51 & 15,58 & 100 & 65 & 118,5 \\
\hline & 2 & 74,55 & 23,89 & 73,50 & 27 & 130,5 \\
\hline & 3 & 54,66 & 23,97 & 52,50 & 25,5 & 112,5 \\
\hline & 4 & 82,71 & 39,11 & 73,50 & 26 & 165 \\
\hline & 5 & 77,46 & 29,05 & 73,50 & 34,5 & 157 \\
\hline & 6 & 70,18 & 28,95 & 65,25 & 31,5 & 156 \\
\hline & 7 & 118,53 & 27,74 & 126,5 & 58,5 & 157 \\
\hline & 8 & 97,70 & 42,86 & 87 & 34 & 177 \\
\hline & 9 & 111,68 & 33,73 & 118,25 & 48 & 169,5 \\
\hline & 10 & 81,15 & 36,50 & 69 & 33 & 156 \\
\hline
\end{tabular}




\section{Advances in Dentistry \& Oral Health}

Table 2: Marginal gap values obtained in HIP groups $(\mu \mathrm{m})$.

\begin{tabular}{|c|c|c|c|c|c|c|}
\hline $\begin{array}{l}\text { Sub } \\
\text { Groups }\end{array}$ & Specimens & Mean & $\begin{array}{r}\text { Standard } \\
\text { Deviation }\end{array}$ & Median & Min. & Max. \\
\hline \multirow{10}{*}{$\begin{array}{c}\text { SHO/ } \\
\text { HIP }\end{array}$} & 1 & 37,66 & 10,48 & 36,25 & 16,5 & 61,5 \\
\hline & 2 & 24,98 & 7,73 & 22,50 & 16,5 & 40,5 \\
\hline & 3 & 33,73 & 15,28 & 34,50 & 16,5 & 78 \\
\hline & 4 & 33,68 & 10,56 & 36 & 16,5 & 57 \\
\hline & 5 & 30,21 & 12,85 & 25 & 16,5 & 61,5 \\
\hline & 6 & 31,83 & 12,55 & 28,50 & 16,5 & 66 \\
\hline & 7 & 41,83 & 10,40 & 73,50 & 36 & 132,5 \\
\hline & 8 & 42,85 & 12,10 & 40,50 & 21,5 & 65 \\
\hline & 9 & 48,35 & 14,81 & 43,25 & 28 & 78 \\
\hline & 10 & 33,38 & 12,00 & 32,25 & 16,5 & 52,5 \\
\hline \multirow{10}{*}{$\begin{array}{c}\text { CHA/ } \\
\text { HIP }\end{array}$} & 1 & 53,15 & 12,68 & 51,75 & 34,5 & 78 \\
\hline & 2 & 40,61 & 13,02 & 39 & 25,5 & 78 \\
\hline & 3 & 43,95 & 6,52 & 43,5 & 34,5 & 58,5 \\
\hline & 4 & 41,61 & 9,53 & 42 & 25,5 & 60 \\
\hline & 5 & 43,83 & 14,53 & 43,50 & 19,5 & 67,5 \\
\hline & 6 & 43,46 & 13,33 & 40,5 & 25,5 & 78 \\
\hline & 7 & 37,30 & 8,50 & 39 & 25,5 & 60 \\
\hline & 8 & 38,65 & 10,51 & 39 & 18 & 54 \\
\hline & 9 & 44,55 & 11,63 & 40,5 & 27 & 78 \\
\hline & 10 & 55,96 & 18,62 & 48 & 34,5 & 102 \\
\hline \multirow{10}{*}{$\begin{array}{l}\text { BEV/ } \\
\text { HIP }\end{array}$} & 1 & 50,51 & 13,37 & 51 & 28,5 & 78 \\
\hline & 2 & 60,15 & 27,94 & 66,75 & 16,5 & 99 \\
\hline & 3 & 67,41 & 28,80 & 62,25 & 32 & 114 \\
\hline & 4 & 41,56 & 17,40 & 39,5 & 15 & 78 \\
\hline & 5 & 48,31 & 25,92 & 49,5 & 16,5 & 93 \\
\hline & 6 & 71,23 & 40,13 & 67,5 & 16,5 & 136 \\
\hline & 7 & 63,58 & 37,71 & 59,25 & 16,5 & 156 \\
\hline & 8 & 45,36 & 19,14 & 48,25 & 16,5 & 78 \\
\hline & 9 & 48,60 & 17,17 & 45 & 16,5 & 78 \\
\hline & 10 & 60,81 & 20,80 & 60,25 & 25,5 & 112,5 \\
\hline
\end{tabular}

Table 3: Marginal gap values of different finish lines $(\mu \mathrm{m})$.

\begin{tabular}{|c|c|c|}
\hline Main Groups & Subgroups & Mean \pm Standard Deviation $(\boldsymbol{\mu m})$ \\
\hline \multirow{3}{*}{ NON-HIP } & SHOULDER & $85,6 \pm 25,6$ \\
\cline { 2 - 3 } & CHAMFER & $60,2 \pm 24,4$ \\
\cline { 2 - 3 } & BEVEL & $86,6 \pm 35,8$ \\
\hline \multirow{3}{*}{ HIP } & SHOULDER & $35,8 \pm 13,5$ \\
\cline { 2 - 3 } & CHAMFER & $44,3 \pm 13,3$ \\
\cline { 2 - 3 } & BEVEL & $55,7 \pm 27,5$ \\
\hline
\end{tabular}

Table 4: The comparison of the same kind of finish lines of two main groups.

\begin{tabular}{|c|c|}
\hline Main Groups & P \\
\hline $\mathrm{SHO} / \mathrm{NHIP}>\mathrm{SHO} / \mathrm{HIP}$ & $<0,001$ \\
\hline $\mathrm{CHA} / \mathrm{NHIP}>\mathrm{CHA} / \mathrm{HIP}$ & $<0,001$ \\
\hline $\mathrm{BEV} / \mathrm{NHIP}>\mathrm{BEV} / \mathrm{HIP}$ & $<0,001$ \\
\hline
\end{tabular}

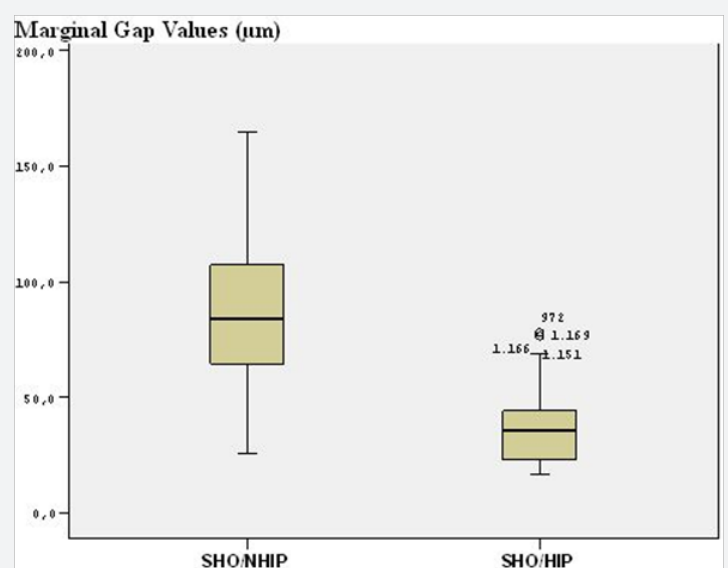

Figure 6: The comparison of shoulder groups.

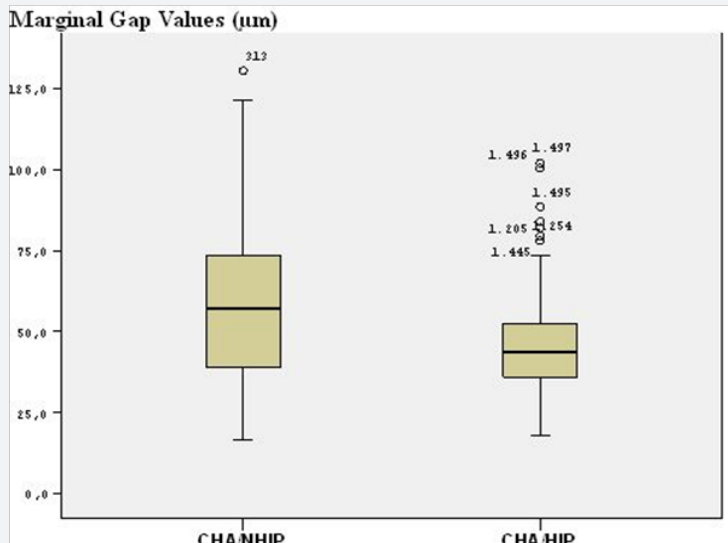

Figure 7: The comparison of chamfer groups.

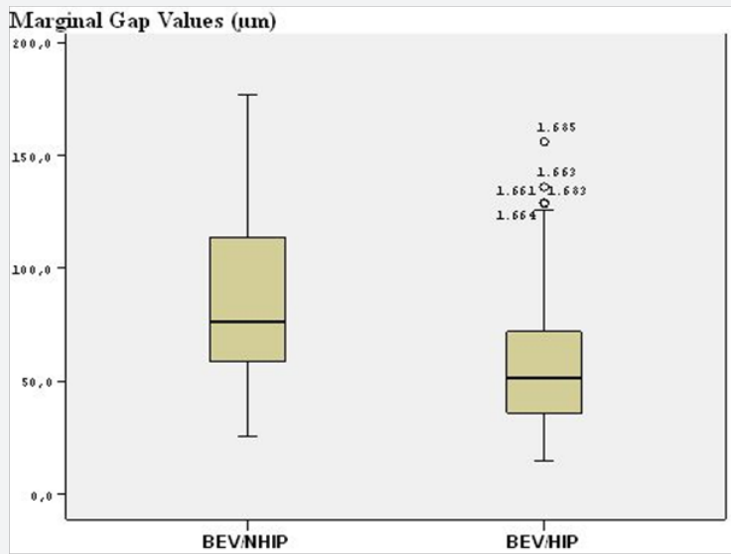

Figure 8: The comparison of bevel groups. 


\section{Discussion}

The purpose of this in-vitro study was to compare the marginal fit of hot isostatic pressed (HIP) and non-hot isostatic pressed (NON-HIP) zirconia copings with 3 different marginal finish lines fabricated with two different CAD-CAM systems. In the current study, 60 stainless steel specimens were fabricated for the simulation of the prepared teeth. Due to the difficulties of ensuring a standard preparation in natural teeth, stainless steel specimens were preferred instead of natural tooth. To ensure standardization, metal or resin dies were used in several studies evaluating the marginal adaptation $[23,24]$. Three finish line design were prepared; shoulder preparation (SHO), chamfer preparation (CHA) and bevel preparation (BEV) $(n=20)$. Each finish line was fabricated twenty items according to the manufacturer's recommendations. 3 experimental groups were divided to two sub-groups includes HIP and NON-HIP based on the zirconium core material type and production method (SHO/HIP, SHO/NHIP, CHA/HIP, CHA/NHIP, BEV/HIP and BEV/NHIP). HIP zirconia specimens were produced by DCS Precedent CAD-CAM system and NON- HIP zirconia specimens were produced by Cerec in Lab CAD-CAM system. According to the results of study the marginal discrepancy of NON-HIP zirconium frameworks was measured as $85,6 \mu \mathrm{m}$ in the shoulder finish line group (SHO/NHIP), $60,2 \mu \mathrm{m}$ in chamfer finish line group (CHA/NHIP) and $86,6 \mu \mathrm{m}$ in bevel finish line group (BEV/NHIP). The marginal discrepancy of HIP zirconium frameworks was measured as $35,8 \mu \mathrm{m}$ in the shoulder finish line group (SHO/HIP), 44, $3 \mu \mathrm{m}$ in chamfer finish line group (CHA/HIP) and 55, $7 \mu \mathrm{m}$ in bevel finish line group (BEV/HIP). The lowest marginal discrepancy amount was found on SHO / HIP group. Based on these findings, the shoulder finish line and hot isostatic pressed group provided better results, thus supporting the hypothesis of the present study. Considering similar studies in the literature, marginal discrepancy values could vary between 28-160 $\mu \mathrm{m}$ [25-27]. However, according to some authors, $200 \mu \mathrm{m}$ is the adequate marginal discrepancy value for an acceptable restoration [28,29]. Coli \& Karlsson [30] reported that the mean value of the marginal gap measurements between the frameworks and the master models was a range of 0 to $115 \mu \mathrm{m}$ and therefore these values were clinically acceptable. Tinschert et al. [31] showed that the measurements of the marginal fit of the FPDs with DC-Zirkon framework exhibited mean marginal discrepancies in a range between 60.5 and $74.0 \mu \mathrm{m}$. Bindl et al. [32] reported that marginal gap width were DCS $(110+/-79 \mu \mathrm{m})$ and Cerec in Lab $(114+/-58 \mu \mathrm{m})$ in their study on 72 specimens. Komine et al. [33] fabricated forty-eight standardized partially sintered $\mathrm{ZrO} 2$ ceramic four-unit FPD frameworks using three different CAD/CAM systems (Cercon Smart Ceramics (group CE), Vita YZ/Cerec In-Lab (group YZ/CL) and Xidex (group XA)) Geometrical means of the marginal discrepancies were evaluated and found a gap amount of 120.0 micro/88.0 micro for the curved/straight design of CE group, 96.8micro/86.5micro for YZ/CL group and 147.3micro/113.4micro for the XA group. They have reported significant differences between straight and curved designs for groups $C E(p=0.001)$ and $X A(p=0.003)$. The marginal discrepancies were significantly smaller in group YZ/CL than in group XA for the curved design and the marginal discrepancies in group YZ/CL were also significantly smaller than those in group CE. These results are consistent with the results of the study considering the difference between shoulder and bevel groups. McLean \& von Fraunhofer [34] proposed that a restoration would be successful if marginal gaps and cement thickness of less than $120 \mu \mathrm{m}$ could be achieved. Among zirconium frameworks fabricated in the current study, the lowest marginal gap values were found in the SHO / HIP group $(35,8 \mu \mathrm{m})$ whereas the highest marginal gap values were observed in the BEV / NHIP group (86, $6 \mu \mathrm{m})$. The entire values were found clinically within acceptable limits. Comparison of the marginal gap values of shoulder and chamfer finish lines it was observed that shoulder finish lines showed more appropriate values in the HIP group (SHO/HIP 35, $8 \mu \mathrm{m}$ ) whereas chamfer finish line showed more appropriate values in the NON-HIP group (CHA / NHIP 60, $2 \mu \mathrm{m}$ ). In our opinion, these differences between the two types of finish lines might result from material differences or the difference of reading parts of CAD-CAM systems. Repeatability is one of the most critical pre-conditions in appropriate measurement of the marginal gap [35]. In the present study; in order to start measuring from the same point of each specimen, guiding points were described (MB, B, DB, ML, L and DL) and marked across of the entire circumference of stainless steel specimens. According to the literature, for the studies focusing on marginal gap measurements, five to twelve specimens were used for each group [36]. We have used ten specimens for each group in our study. It has been proclaimed that, one of the most important parameters is the standard deviation of measured marginal gap and an acceptable standard deviation is thought to be approximately $20 \mu \mathrm{m}[15,18,22,37]$. In the current study, standard deviation values were calculated from $13,5 \mu \mathrm{m}$ to 35 , $85 \mu \mathrm{m}$. Especially $35,85 \mu \mathrm{m}$ standard deviation value was obtained on the partially sintered bevel finish line group. The reason of this value could be attributed to the undulated shrinkage during sintering of blocks with porous structure.

\section{Conclusion}

The marginal gap of frameworks obtained from fully sintered zirconia blocks was smaller than the marginal gap of frameworks obtained from partially sintered zirconia blocks. The amount of marginal gap at zirconium frameworks has been affected by the type of finish line. The amount of marginal gap of shoulder and chamfer type finish lines presented with smaller gaps than the bevel type finish line. Average values of six experimental groups were found under $120 \mu \mathrm{m}$, which were all within clinically acceptable limits. Further investigations are necessary in this field, even if the quality of marginal fit depends on the CAD/ CAM system used.

\section{Acknowledgement}

Presented at the $18^{\text {th }}$ Congress of the Balkan Stomatological Society (Bass), Skopje, Macedonia, April 2013. 


\section{References}

1. Raigrodski Ariel J, Chiche Gerard J (2001) The safety and efficacy of anterior ceramic fixed partial dentures: A review of the literature. J Prosthet Dent 86(5): 520-525.

2. Rosentiel SF, Land MF, Fujimoto J (2001) Contemporary fixed prosthodontics. The C V Mosby Company, Missouri, USA.

3. (1991) Estimates of dental services completed in 1990 by private practitioners by dental specialty, 1990 survey of dental services rendered and distribution of dentists in the US by region and state. American Dental Association, Survey Center, Chicago, USA.

4. Boening KW, Walter MH, Reppel PD (1992) Non-cast titanium restorations in fixed prosthodontics. J Oral Rehabil 19(3): 281-287.

5. Burstone CJ, Goldberg AJ (1980) Beta titanium: a new orthodontic alloy. Am J Orthod 77(2): 121-132.

6. (2001) EPA Chronic Toxicity Summary. Beryllium and Beryllium Compounds, US.

7. Schwickerath H (1998) Ceramic-metal crowns. Quintessenz Zahntech German 14(10): 1147-1151.

8. Akın E (1990) Diș Hekimliğinde Porselen. (III. Baskı) İ Ü Basım Evi ve Film Merkezi İstanbul (7-10): 232-234

9. Kelly Robert J, Nishimura I, Campbell Stephen D (1996) Ceramics in dentistry: Historical roots and current perspectives. J Prosthet Dent 75(1): 18-32.

10. Sadowsky SJ (2006) An overview of treatment considerations for esthetic restorations: A review of the literature. J Prosthet Dent 96(6): 433-442.

11. Holmes RJ, Bayne CS, Holland AG, Sulik DW (1989) Considerations in measurements of marginal fit. J Prosthet Dent 62(4): 405-408.

12. Stappert CFJ, Dai M, Chitmongkolsuk S, Gerds T, Strub JR, et al. (2004) Marginal adaptation of three-unit fixed partial dentures constructed from pressed ceramic systems. Br Dent J 196(12): 766-770.

13. Yeo I, Yang J, Lee J (2003) In vitro marginal fit of three all-ceramic crown systems. J Prosthet Dent 90(5): 459-464.

14. Abbate FM, Tjan AHL (1989) Comparison of the marginal fit of various ceramic crown systems. J Prosthet Dent 61(5): 527-531.

15. Alkumru H, Hullah WR, Marquis PM, Wilson HJ (1988) Factors affecting the fit of porcelain jacket crowns. Br Dent J 164(2): 39-43.

16. Anusavice KJ, Philips H (1996) Science of Dental Materials, 10TH ED. WB Saunders Company, Philadelphia, London, Toronto, Montreal, Sydney, Tokyo.

17. Suarez MJ, Villaumbrosia PG, Lozano JFL (2003) Comparison of the marginal fit of procera allceram crowns with two finish lines. Int J Prosthodont 16(3): 229-232.

18. Davis DR (1988) Comparison of fit of two types of all-ceramic crowns J Prosthet Dent 59(1): 12-16.

19. Witkowski S (2006) CAD/CAM in dental technology. Quint Dent Technol. In PhD thesis of Von Kassiani Stamouli entitled Fracture resistance of different zirconia three-unit posterior all-ceramic fixed partial dentures, pp. 1-16.
20. Griggs JA (2007) Recent advances in materials for all-ceramic restorations. Dent Clin North Am 51(3): 713-727.

21. Besimo CE, Spielmann HP, Rohner HP (2001) Computer-assisted generation of all-ceramic crowns and fixed partial dentures. Int J Comput Dent 4(4): 43-62.

22. Luthardt RG, Rieger W, Musil R (1997) Grinding of ziroconia-TZP in dentistry- CAD/CAM- technology for the manufacturing of fixed dentures. In: Sedel L, Rey C (Eds.), $10^{\text {th }}$ International Symposium on Ceramics in Medicine Bioceramics 10, Elsevier, Paris, France, Netherlands, pp. 437-440.

23. Cho LR, Choi JM, Yi YJ, Park CJ (2004) Effect of finish line variants on marginal accuracy and fracture strength of ceramic optimized polymer/fiberreinforced composite crowns. J Prosthet Dent 91(6): 554-560.

24. Syu JZ, Byrne G, Laub WL, Land FM (1993) Influence of finish line geometry on the fit of crowns. Int J Prosthodont 6(1): 25-30.

25. Hung SH, Hung KS, Eick JD, Chappell RP (1990) Marginal fit of porcelain-fused-to metal and two types of ceramic crown. J Prosthet Dent 63(1): 26-31.

26. Rinke S, Hüls A, Jahn L (1995) Marginal accuracy of conventional and copy-milled all-ceramic crowns. Int J Prosthodont 8(4): 303-310.

27. Ural C, Burgaz Y, Saraç D (2008) Farklı yöntemlerle yapılan porselen restorasyonların kenar uyumlarının tarayıcı elektron mikroskobu ile değerlendirilmesi. Ondokuz Mayis Univ Diş Hek Fak Derg 9(1): 22-27.

28. Gulker I (1985) Margins. Dent J 51: 213-217.

29. Hunter AJ, Hunter AR (1990) Gingival margins for crowns: A review and discussion. Part II: Discrepancies and configurations. J Prosthet Dent 64(6): 636-642.

30. Coli P, Karlsson S (2004) Fit of a new pressure-sintered zirconium dioxide coping. Int J Prosthodont 17(1): 59-64.

31. Tinschert J, Natt G, Mautsch W, Spiekermann H, Anusavice KJ, et al. (2001) Marginal fit of alumina-and zirconia-based fixed partial dentures produced by a CAD/CAM system. Oper Dent 26(4): 367-374.

32. Bindl A, Mormann WH (2005) Marginal and internal fit of all-ceramic CAD/CAM crown-copings on chamfer preparations. J Oral Rehabil 32(6): 441-447.

33. Komine F, Gerds T, Witkowski S, Strub J R. (2005) Influence of framework configuration on the marginal adaptation of zirconium dioxide ceramic anterior four-unit frameworks, Acta Odontol Scand 65(3): 361-366

34. McLean JW, Von Fraunhofer JA (1971) The estimation of cement film thickness by an in vivo technique. Br Dent J 131(3): 107-111.

35. Beschindt SM, Strub J (1999) Revaluation of the marginal accuracy of different allceramic crown systems after simulations in the artificial mouth. J Oral Rehabil 26(7): 582-593.

36. Yavuzyılmaz H, Turhan B, Bavbek B, Kurt E (2005) Tam porselen sistemleri II. GÜ Diş Hek Fak Derg 22: 49-60.

37. Balkaya M C, Çınar A, Pamuk S (2005) Influence of firing cycles on the margin distortion of 3 all-ceramic crown systems. J Prosthet Dent 93(4): 346-355. 
Your next submission with Juniper Publishers will reach you the below assets

- Quality Editorial service

- Swift Peer Review

- Reprints availability

- E-prints Service

- Manuscript Podcast for convenient understanding

- Global attainment for your research

- Manuscript accessibility in different formats ( Pdf, E-pub, Full Text, Audio)

- Unceasing customer service

Track the below URL for one-step submission https://juniperpublishers.com/online-submission.php 